\title{
REVERSE APPLICATION OF MSA TOOL FOR CMM STYLUS EVALUATION
}

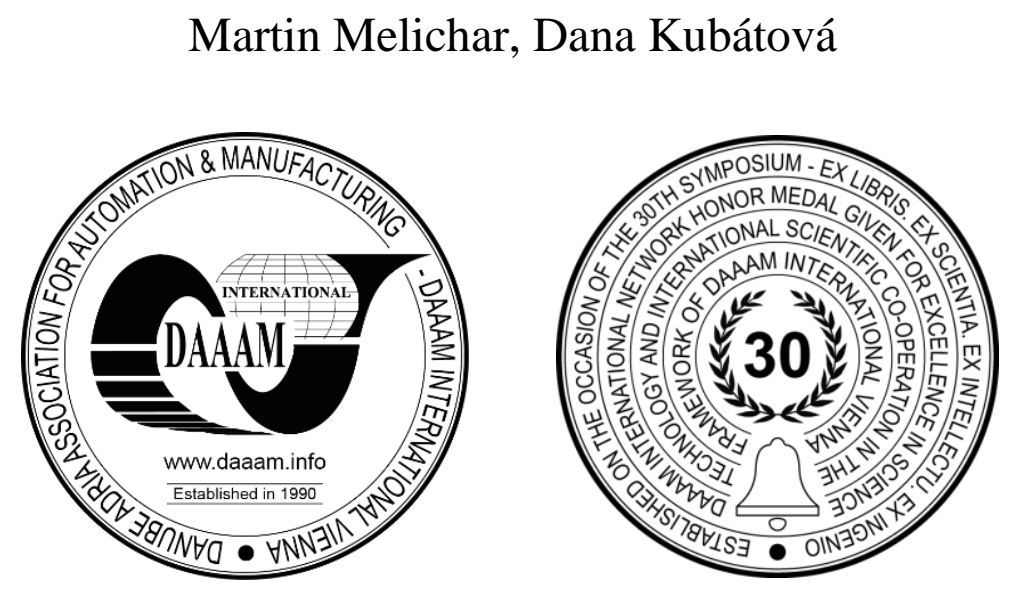

This Publication has to be referred as: Melichar, M[artin] \& Kubatova, D[ana] (2019). Reverse Application of MSA Tool for CMM Stylus Evaluation, Proceedings of the 30th DAAAM International Symposium, pp.0390-0393, B. Katalinic (Ed.), Published by DAAAM International, ISBN 978-3-902734-22-8, ISSN 1726-9679, Vienna, Austria DOI: $10.2507 / 30$ th.daaam.proceedings.053

\begin{abstract}
In today's robust quality management systems, final inspection is a critical process that often determines the success of the entire production. For this reason, the most accurate measuring instruments available to the manufacturer are used in the final inspection and the measurements take place under controlled conditions of metrology laboratories. A very frequently used device, valued for its versatility and accuracy, is CMM. Modern CMM machines achieve high precision by the touch method below $1 \mu \mathrm{m}$ and versatility achieved through a wide range of movements. The article describes an experiment during which a reverse application of the MSA method was performed to verify the effect of stylus diameter on variability in the measurement process. The results of an experiment carried out in an accredited metrology laboratory show a significant influence of this parameter on the overall measurement accuracy.
\end{abstract}

Keywords: MSA; CMM; Stylus; metrology; automotive industry

\section{Introduction}

CMM measurement and inspection is one of the key operations of many manufacturing processes today. Thanks to measuring speed and accuracy, modern portal machines enable a productive way of determining the actual values of the inspected parameters. [1] This versatility and productivity is ensured by the wide range of movements on the one hand and by the number of usable touches on the other. It is not unusual that a wide range of different touches is used during single program run. This variability of the measurement process brings an undeniable influence on the results and evaluation of the obtained data. [7]

After a thorough literary research, the team of authors concluded that it is appropriate to analyse the problem in more depth and possibly to design a simple methodology that could be easily applied in the industrial practice in which this problem is commonly encountered.

The performed experiment and statistically processed data then clearly showed a significant influence between the operator's proposed measurement strategy (represented by the used touches) and the suitability / unsuitability of the entire measurement system. [6] 
For the evaluation of the impact, a transformed (reverse) MSA methodology was used, which, instead of the influence of individual operators on the measurement system, evaluates the influence of used contacts in relation to the MSA parameter GRR. [4] This evaluated parameter clearly identified the indisputable influence that could potentially endanger the measurement system in its basic rules and particulars, see the "golden rule of metrology" [10]. This experiment, including evaluation, will be part of a comprehensive study at RTI at the Faculty of Mechanical Engineering, University of West Bohemia in Pilsen. The study will comprehensively address the methodology of CMM measurement with the aim of minimizing variability caused by external influences. [9]

\section{Experiment}

The basic data of the experiment was collected in the RTI metrology laboratory. The laboratory provides ideal conditions for controlled experiments as it provides controlled environmental conditions (temperature $20 \pm 1^{\circ} \mathrm{C}$, humidity $50 \pm 10 \%$ ) in addition to strictly calibrated equipment and highly qualified personnel. A highly sophisticated CMM Carl Zeiss Prismo 7 Navigator was used as a measuring device, which in addition to a high degree of universality also allows for highly accurate measurements with an uncertainty of less than $1 \mu \mathrm{m}$. A test sample, which was represented by an accurate calibration ring of known diameter, was repeatedly measured using this device.

The main question was how to verify the impact of the touches themselves credibly and easily. In the end, the MSA methodology proved to be appropriate. The MSA methodology assesses the repeatability and reproducibility of the measurement system in relation to the operators that perform the measurement. For this standard experiment, it would be necessary to have 10 samples of the same type, which 3 operators would measure 3 times under the same conditions.

In the case of impact assessment of styluses, the authors decided to transform the methodology. The whole measurement was then carried out using an automatic machine cycle (with repeated use of the program) and was carried out by single operator. The variable "operator" of MSA was replaced in the MSA reverse methodology environment by parameter "stylus diameter" and 10 samples were replaced by single sample, but measured different number of scanned points. So what does that mean? Instead of 3 operators who measure 10 pieces of samples 3 times, team has 1 operator with 3 styluses of different diameters to measure 1 sample 10 times with different number of points (6 to 100 points).

\subsection{Input parameters of the experiment:}

- Operator: single

- Etalon: calibrated steel ring diameter $90 \mathrm{~mm}$

- Styluses: 1,5mm, 3mm, 5mm (all on the non-indexable CMM head Vast Gold)

- Number of touch points (represent different parts): 6pts, 8pts, 12pts, 14pts, 16pts, 30pts, 100pts

- Repeat measurements: 10 times for each stylus and "part"

- Environment conditions temperature $=20 \pm 1^{\circ} \mathrm{C}$, humidity $=50 \pm 10 \%$ humidity [8]

- On purpose, critical parts for automotive industry were selected whose tolerance was on the order of $\pm 0.01 \mathrm{~mm}$ (Fig.3)

- Theoretical errors:

- Machine's repeatability error [3]

○ Chosen stylus tip - e.g. its diameter

- Program error [5]



Fig. 1. Zeiss Prismo7 Navigator

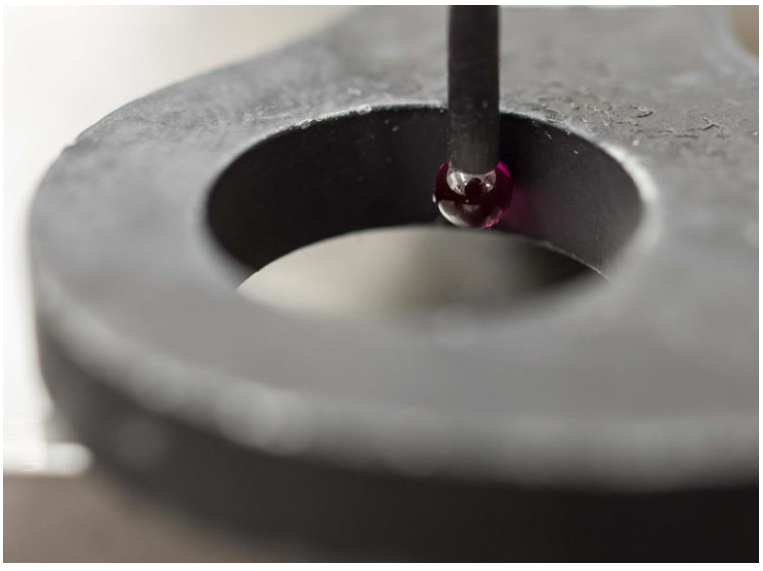

Fig. 2. Touch stylus during measurement [2] 


\section{Data processing}

\begin{tabular}{|c|c|c|c|c|c|c|c|c|}
\hline \multicolumn{2}{|c|}{$\begin{array}{c}\text { Stylus } \\
\text { Meas. series }\end{array}$} & $6 \mathrm{pts}$ & 8 pts & $12 \mathrm{pts}$ & 14 pts & $16 \mathrm{pts}$ & 30 pts & $100 \mathrm{pts}$ \\
\hline \multirow{10}{*}{$1,5 \mathrm{~mm}$} & 1 & 90,00002 & 89,99988 & 90,00007 & 89,99988 & 89,99998 & 89,99993 & 89,99993 \\
\hline & 2 & 90,00011 & 89,99990 & 90,00013 & 89,99992 & 90,00001 & 89,99994 & 89,99994 \\
\hline & 3 & 90,00013 & 89,99992 & 90,00015 & 90,00001 & 90,00004 & 90,00000 & 90,00000 \\
\hline & 4 & 89,99948 & 89,99933 & 89,99958 & 89,99935 & 89,99942 & 89,99947 & 89,99947 \\
\hline & 5 & 89,99973 & 89,99954 & 89,99974 & 89,99950 & 89,99962 & 89,99967 & 89,99967 \\
\hline & 6 & 89,99987 & 89,99959 & 89,99983 & 89,99962 & 89,99971 & 89,99965 & 89,99965 \\
\hline & 7 & 90,00002 & 89,99988 & 90,00007 & 89,99988 & 89,99998 & 89,99993 & 89,99993 \\
\hline & 8 & 90,00011 & 89,99990 & 90,00013 & 89,99992 & 90,00001 & 89,99994 & 89,99994 \\
\hline & 9 & 90,00013 & 89,99992 & 90,00015 & 90,00001 & 90,00004 & 90,00000 & 90,00000 \\
\hline & 10 & 89,99948 & 89,99933 & 89,99958 & 89,99935 & 89,99942 & 89,99947 & 89,99947 \\
\hline \multicolumn{2}{|c|}{ Average } & 89,99993 & 89,99974 & 89,99996 & 89,99976 & 89,99985 & 89,99982 & 89,99982 \\
\hline \multicolumn{2}{|c|}{ Spread } & 0,00066 & 0,00059 & 0,00057 & 0,00066 & 0,00062 & 0,00052 & 0,00052 \\
\hline
\end{tabular}

Table 1. 1,5mm stylus data

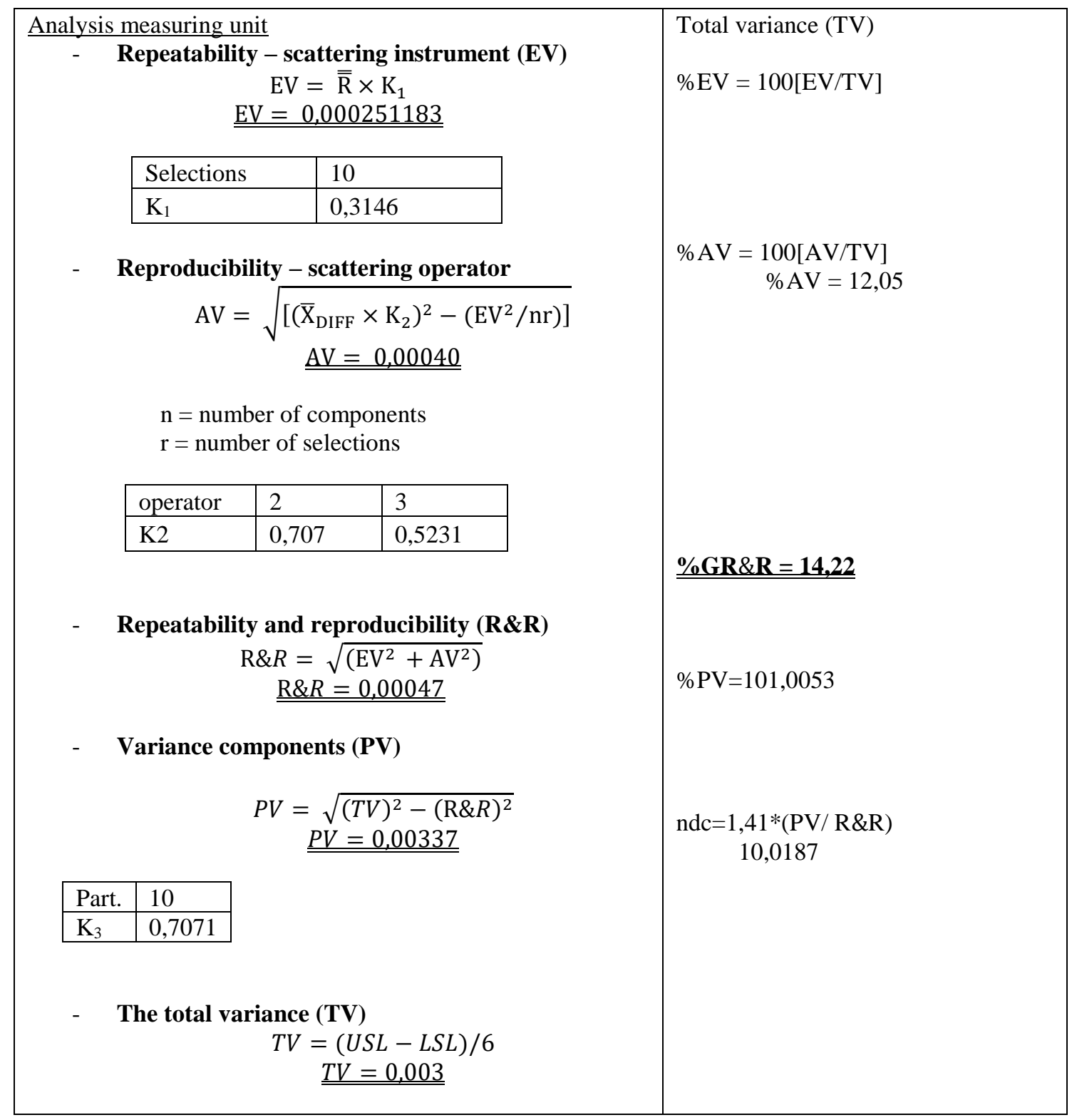

Table 2. Parameter GRR evaluation 


\section{Conclusion}

This article describes influence of various styluses during measuring process. The key feature of final inspection especially by using CMM is to ensure that the results can be trusted by supplier and the customer through whole production process. There were key questions at the beginning of the experiment - How can different styluses affect the precision of inspection process and how can the operator or the company quantify this precision to ensure it is acceptable for specific industry application. At the UWB, Faculty of Mechanical Engineering, Metrology lab the experiment was performed - using coordinate measuring device precise etalon ring was measured repeatedly. A methodology based on the standard MSA method was designed to process the obtained data. This methodology makes it possible to relate the obtained data to the measuring system/method by indicating the percentage consumption tolerance from the drawing that devalues the system by used stylus. The advantage of this methodology is usage of automatic machine cycle with the presence of a single operator, which represents a significant personnel and time savings over the standard MSA methodology. The result of the experiment and the data processing showed an unpleasant, albeit expected fact. Although accuracy and uncertainty close to $1 \mu \mathrm{m}$ can be achieved on high-precision 3D measuring machines with one-touch measurements, degradation of the system and consequently results from the use of multiple styluses is presented. For data processing, the theoretical tolerance of the measured standard has been set to $\pm 0.01 \mathrm{~mm}$ to meet the requirements of the IATF standard for the automotive industry. This requirement tightens the "golden rule of metrology" by requiring that the measuring equipment used to be at least 20 times more accurate than the parameter measured by it. The GRR parameter as a result of the MSA methodology clearly shows that although the operator appropriately selected the metering device and methodology at the beginning of the experiment, the results obtained and influenced by the use of multiple touches lose credibility. This measurement burdened by this methodology can then be used in the automotive industry only for non-critical and non-significant parameters or with the sole consent of the customer. The question posed at the beginning of the experiment: how the use of different touches will affect the accuracy of the measurement? Can therefore clearly be said to be very negative. However, taken from the opposite side of the problem, if the operator appropriately chooses a CMM measurement touch so that it does not need to be changed during the measurement cycle, its measurement in accuracy and measurement relevance can be matched by much more expensive and more accurate equipment. The question posed at the beginning of the experiment: how the use of different touches will affect the accuracy of the measurement can therefore clearly be said to be very negative. However, taken from the opposite side of the problem, if the operator appropriately chooses a CMM measurement touch so that it does not need to be changed during the measurement cycle, its measurement in accuracy and measurement relevance can be matched by much more expensive and more accurate equipment. This experiment and the article are part of a study conducted during the years 2016-2020, which aims to comprehensively analyse the factors affecting the measuring CMM process.

\section{Acknowledgments}

This paper was created due to the project GA ZCU v Plzni: SGS-2019-008 "Research and development for innovation in field of Manufacturing processes - Technology of metal cutting III

\section{References}

[1] ZEISS [online]. [cit. 2018-09-15].

[2] Jirouek, P.: Eligibility of measurement system in the gearboxes production of Škoda auto a.s (2012) [online]. [cit. 2017-03-08].

[3] http://www.consultantiso17025.com/Uncertainty_of_measurement_UOM_calculations_for_ISO_ 17025.html [online]. [cit. 2018-09-15].

[4] Melichar M., Kubátová D., Kutlwaše J.: (2016). CMM measuring cycle and human factor, Proceedings of the 27th DAAAM International Symposium, ISBN 978-3-902734-08-2

[5] Pernikař, J.: Assessment of the competence of control means [online]. [cit. 2016-11-25]. Available from: http://gps.fme.vutbr.cz/STAH_IN FO/31_Pernikar_VUTBR.pdf

[6] Płowucha W., Jakubiec W., Wojtyła M.: Possibilities of CMM Software to Support Proper Geometrical Product Verification, Procedia CIRP, Volume 43, 2016, Pages 303-308, ISSN 2212-8271, http://dx.doi.org/10.1016/j.procir.2016.02.124 .

[7] Barini M. E., Tosello G. Chiffre d L.: Uncertainty analysis of point-by-point sampling complex surfaces using touch probe CMMs: DOE for complex surfaces verification with CMM, Precision Engineering, Volume 34, Issue 1, January 2010, Pages 16-21, ISSN 0141-6359, http://dx.doi.org/10.1016/j.precisioneng.2009.06.009 .

[8] D. Kubátová, M. Melichar, J. Kutlwašer, Evaluation of Repeatability and reproducibility of CMM equipment, In Procedia Manufacturing, Volume 13, 2017, Pages 558-564, ISSN 2351-9789, https://doi.org/10.1016/j.promfg.2017.09.091.

[9] Melichar, M; Kubatova, D;Kutlwaser, J.: (2017). Influence of CMM Velocity on Scanning Precision, Proceedings of the 28th DAAAM International Symposium, pp.0400-0409, B. Katalinic (Ed.), Published by DAAAM International, ISBN 978-3-902734-11-2, ISSN 1726-9679, Vienna, Austria DOI: 10.2507/28th.daaam.proceedings.056

[10] Bicova, K[aterina] \& Bebr, L[ukas] (2018). Analysis and Dependability of Production Processes for the Automotive Industry, Proceedings of the 29th DAAAM International Symposium, pp.0416-0420, B. Katalinic (Ed.), Published by DAAAM International, ISBN 978-3-902734-20-4, ISSN 1726-9679, Vienna, Austria DOI: 10.2507/29th.daaam.proceedings.061 